\title{
Ten years of the China migrants dynamic survey: retrospective and prospects
}

\section{Zhili Wang ${ }^{1} \cdot$ Qian Wang ${ }^{2} \cdot$ Jianan $\mathrm{Qi}^{1}{ }^{10}$}

Received: 15 June 2021 / Accepted: 26 August 2021 / Published online: 10 September 2021

(c) The Author(s) 2021

\begin{abstract}
This paper reviews the background of China's decision to launch the "China Migrants Dynamic Survey" (CMDS), and examines the ideas and characteristics of CMDSs carried out annually from 2009 through 2018. The paper considers such aspects as project design, questionnaire design, sampling design, and survey implementation, and summarizes why it is necessary to carry out CMDS and the survey's performance. Based on the need for information that drives migration surveys and research in the new era, and taking into account the experience gained from previous surveys, this paper attempts to set forth several issues that need to be taken into consideration in the design and implementation of future surveys of migrants.
\end{abstract}

Keywords Migration · Survey · China Migrants Dynamic Survey (CMDS)

\section{Introduction}

Since the roll-out of the reforms and opening-up policy in 1978, China has witnessed a surge in domestic migration, especially the massive cross-regional flow of rural labor from inland to coastal areas and from rural to urban areas. Masses of migrants, because they are the most active factor of production, have not only supported the China's burgeoning economic development and hastened the pace of modernization, but have also propelled the in-depth development of the market economy and institutional reforms, and triggered profound social changes in a variety of areas. These areas of change include the distribution of the labor force among industries and occupations, the urban-rural distribution of population, the class structure of society, the lifestyle and values of the rural labor force, the development of new laws and regulations, and the articulation of government functions, among others.

Jianan Qi

jianan_qi@126.com

1 China Population and Development Research Center, Beijing, China

2 National Health Commission of People's Republic of China, Beijing, China 
China's population censuses and related population sample surveys have pointed to the soaring growth of the migrant population in China. During the 33 year period from 1982 to 2015, China's migrant population surged from 6.57 million to nearly 247 million, an increase of 36.6 times. The sheer size of the migrant population has become a pivotal factor since the reforms and opening began, that continues to have a tremendous impact on national and regional economic development, industrial structure, social construction, ecological civilization, social governance, and the provision of public services (Fig. 1).

Population migration has driven adjustments to China's economic structure and the transformation of the country's economic growth mode. Internal migration has been a key factor underpinning China's push to gradually transform its dual urban-rural structure, to advance the construction of a new socialist countryside, to speed up urbanization and to accomplish the goal of urban-rural integration. In order to effectively ensure population security, through the surveys to better understand the patterns of migration and to analyses their underlying driving forces, it is imperative measure to bridge the data of migrants and policy-making. Therefore, the governments can strengthen the services for and the management of migrants, and comprehensively address the problems arising between rural and urban, peasants and citizens, tradition and modernity, separation and integration.

\section{Backgrounds for emergence of CMDS}

As the size of the migrant population has increased steadily, concerns about services for and the management of migrants, as well as the need for accurate information about population migration, have drawn the attention of both government and academia. Duan et al., (2002) reviewed the migration surveys carried out before the fifth national census in 2000 (as shown in Table 1). Cities with a large number of migrants, such as Beijing and Shanghai, launched their own special surveys

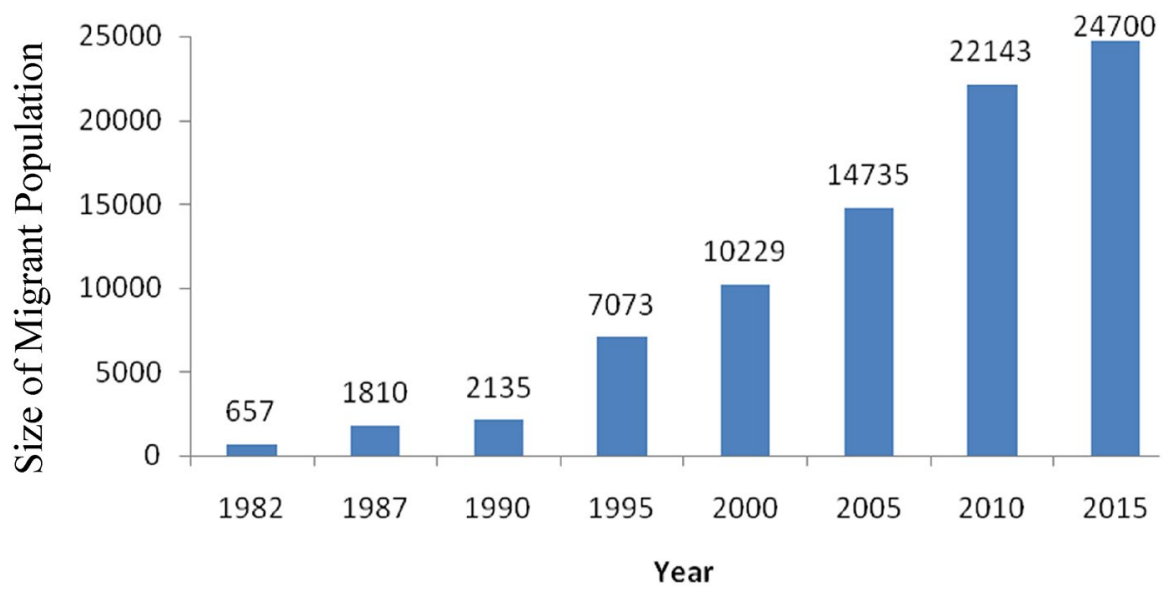

Fig. 1 Changing trend of the size of migrant population since the reforms and opening began. Source: the databook of every census and $1 \%$ population sampling surveypublished by China National Bureau of Statistics since 1982 


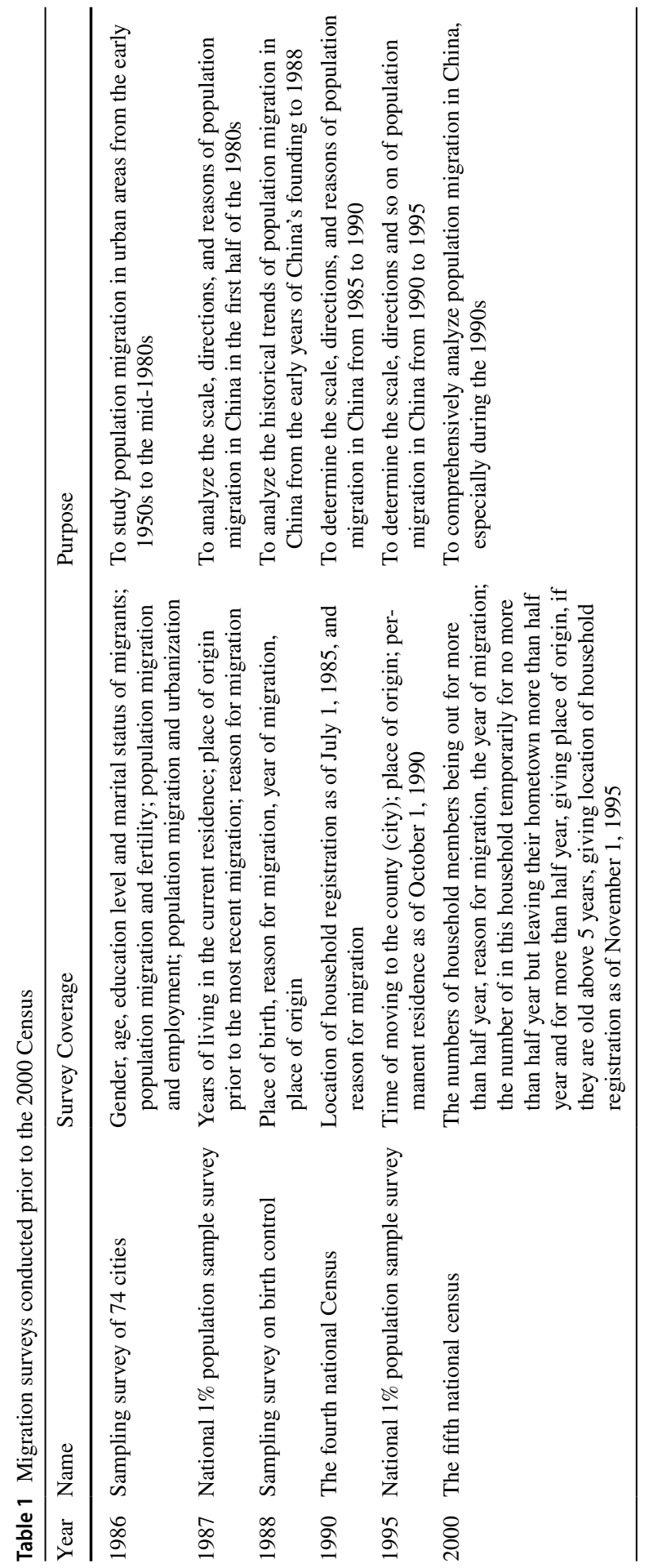


of migrants in 1985; Beijing even conducted a census of the migrant population in 1997. Chongqing, Xi' an, Shenzhen, and several other cities also completed migration surveys in the late 1980s or the1990s (Duan et al., 2002).

As part of the State Council's 2008 institutional reform scheme, which was designed to define the duties, divisions and staffing of government agencies, the former National Population and Family Planning Commission (NPFPC) added the Department of Services and Management for the Migrant Population to highlight the government's high concern for the management of family planning and related services for the migrant population. The Department of Services and Management for Migrant Population proposed to set up a migration survey program and to improve the system for the rapid collection, dynamic monitoring, and systematic analysis of family planning data for migrants. By giving full play to its extensive grass-roots network, bountiful research resources, professional teams, strong IT foundation and rich experience in monitoring and managing statistics, the population and family planning system can regularly collect statistical data and organize surveys in parts of China where there are concentrations of migrants living. Data collection and surveys provide timely information of changes in migrant populations, and allow effective monitoring of basic information about migrants and their work, living situations and other life trajectories. An overview of the temporal and spatial distribution and socioeconomic characteristics of migrants can be developed, allowing for analysis of the institutional design and socioeconomic factors that affect the behaviors of migrants. This effort supports the improvement of the migrant service and management system and the formulation of policies related to the system.

CMDSs were introduced in response to China's push to establish a migrant survey system. It effectively collects and applies basic information about migrants to support China's needs to formulate and implement relevant national policies and programs.

The dynamic survey of the migrant population and the timely release of migrant service and management alerts can help China achieve the goals of creating a system "guided by information", maintaining a timely and accurate grasp of the current status of migrant services and management, upgrading services for migrants, and introducing innovative management mechanisms.

\section{Practices of CMDSs in 10 years}

From 2009, the department of migrant began to conduct a five-city migrant survey for test, and implemented the last survey in 2018. The surveys had been carried out annually with a steady survey framework, and proved to be really effective.

\subsection{Migrants covered by CMDSs}

CDMSs target those migrants who are 15 years old and above, have lived in destinationthe destination area for more than one month and who do not hold a hukou (household registration) for the location where they are living. The CMDSs are 
comprised of two types of information and adopt an $\mathrm{N}+\mathrm{X}$ model: basic information

(N) and key information (X) about migrants' participants.

1. Basic information about migrants $(\mathrm{N})$ : includes such basic information as age, gender, marital status, range and reason for migrants and the information on employment, family planning services and management.

2. Key information about migrants $(\mathrm{X})$.

The key information about migrants helps to reveal the socioeconomic activities and family planning/reproductive health status of migrants, which vary with the situations and needs of annual object.

\subsection{Sampling design of CMDS}

Because the spatial distribution of migrants is variable and uneven, it is difficult to draw up a sampling frame and develop a sampling design (Zhuang \& Li, 2014). In order to make the survey data representative of both the whole country and the respective provinces (regions/municipalities) as well, it was decided to base the sampling frame on the annual migration report databases from all 31 provinces (regions/ municipalities) and the Xinjiang Production and Construction Corps, and to adopt a stratified, multi-stage PPS sampling method. The sampling for each year of the survey maintains good consistency and continuity in terms of the hierarchy, with townships (towns/sub-districts) being the primary sampling units. These are sorted pursuant to such characteristics as age, gender and the number of their family members 15 years old and above who are living together (Qi et al., 2014).

When sampling townships (towns/sub-districts) during the first stage of the 2009 survey, a stratification scheme based on three strata (township, sub-district, and factory/mine/enterprise) was adopted for areas with concentrations of migrants. In 2010 and later surveys, a three stage sampling scheme was used. Townships (towns/ sub-districts) were sampled using PPS in the first stage. Next, in the second stage, villages or neighborhoods in townships (towns/sub-districts) selected in stage one were sampled using PPS. Finally, individual respondents from villages or neighborhoods selected in stage two were sampled in the third stage. A two-phase sampling method was adopted to systematically sample individuals who were sorted by basic information, i.e. gender, age, length of residence, etc. (Qi et al., 2014).

\subsection{Main characteristics of CMDSs}

While emphasizing destination areas and taking into account orientation areas, the CMDSs have made use of the extensive service and management network of the population and family planning system to conduct door-to-door household surveys of migrants. The presentation of CMDSs have the following characteristics:

1. Put emphasis on destination areas and takes into account orientation areas to reveal the life, survival and development of migrants in destination areas. 
2. The targets of the surveys are those who have left the locale of their household registration (hukou) to live in another place for the sake of work and life, as well as those who move with them.

3. CMDSs combine long-interval surveys (annual) with short-interval surveys (quarterly) of key issues to gain a comprehensive understanding of not only long-term trends but short-term incidents as well (such as the employment situations of migrant workers in coastal areas before and after the Spring Festival).

4. Combine basic information with key information to get an overarching picture of both overall trends and the survival and development of migrants in specific settings as well.

\subsection{Changes of CMDSs in 10 years}

Survey targets and survey coverage have changed over time with the advancement of CMDS and the changes in survey context. From 2009 to 2011, CMDS targeted migrants 16-59 years of age to survey their basic family status, employment status, social security, life, children, and access to family planning services, against the backdrop of the Asian financial crisis and the emergence of labor shortages which prompted the theoretical explorations of the "Lewis Turning Point". From 2012 to 2014, CMDS targeted migrants aged 15-59 years, which, from a demographic perspective, is a more standardized age range for the working-age population. With regard to survey coverage, and with the institutional reforms, CMDSs started to place greater emphasis on basic family planning public services and healthcare security. As the aging of China's population accelerated and, given the existence of this phenomenon in the migrant population, CMDSs expanded the survey targets to include migrants aged 65 years and above in 2015, and added survey questions related to medical services for the elderly. In the context of rapid urbanization, CMDSs further expanded the survey targets to include "half-households" with either husband or wife holding a hukou of the destination area, and began to focus more on the social integration of migrants. The sample size of the survey has changed every year based on the scope, coverage, and theme of the survey (Tables 2, 3).

\subsection{Main results of the survey}

The CDMSs over a ten year period have produced fruitful results. The National Health Commission (formerly, at different times, the National Population and Family Planning Commission and the National Health and Family Planning Commission) publishes an annual report titled the Report on China's Migrant Population Development. This report focuses on major national strategic plans and key development policies, and uses detailed survey data to provide an in-depth analysis of the developments of and the changes in the migrant population. Based on this analysis, the report makes policy recommendations, thereby playing a pivotal role in shedding light on the overall conditions of the migrant population, supporting the development of services for and the management of migrants, and publicizing research results related to the migrant population. 
Table 2 Scope, targets, and sample size of CMDS surveys from 2009 to 2018

\begin{tabular}{lllc}
\hline Year & Scope & Targets & Sample Size \\
\hline 2009 & $\begin{array}{c}\text { Including 5 key cities (Beijing, Taiyuan, } \\
\text { Shanghai, Shenzhen, and Chengdu) }\end{array}$ & Migrants aged 16-59 years & 47,000 \\
2010 & Covering 106 cities & Migrants aged 16-59 years & 122,000 \\
2011 & Nationwide (urban-rural disaggregated) & Migrants aged 16-59 years & 128,000 \\
2012 & Nationwide (urban-rural disaggregated) & Migrants aged 15-59 years & 159,000 \\
2013 & Nationwide (urban-rural disaggregated) & Migrants aged 15-59 years & 199,000 \\
2014 & Nationwide (urban-rural disaggregated) & Migrants aged 15-59 years & 201,000 \\
2015 & Nationwide (urban-rural disaggregated) & Migrants aged 15 and above & 206,000 \\
2016 & Nationwide (urban-rural disaggregated) & Migrants aged 15 and above, including & 169,000 \\
& & half-households & Migrants aged 15 and above, including \\
2017 & Nationwide (urban-rural disaggregated) & 170,000 \\
& & half-households & \\
2018 & Nationwide (urban-rural disaggregated) & Migrants aged 15 and above, including & 152,000 \\
& & half-households & \\
\hline
\end{tabular}

Table 3 Main coverage of CMDS surveys from 2009 to 2018

\begin{tabular}{|c|c|}
\hline Year & Survey Coverage \\
\hline 2009 & $\begin{array}{l}\text { Family members and basic information about the family; personal information, migration } \\
\text { experience, employment status, social security, life, living situation, etc }\end{array}$ \\
\hline $2010(1 \mathrm{H})$ & $\begin{array}{l}\text { Basic information, children, employment, social security, health and family planning ser- } \\
\text { vices, housing, life, etc }\end{array}$ \\
\hline $2010(2 \mathrm{H})$ & $\begin{array}{l}\text { Basic information, employment, housing, children, access to family planning services, social } \\
\text { participation, etc }\end{array}$ \\
\hline 2011 & $\begin{array}{l}\text { Basic information, employment, housing, children, access to family planning services, social } \\
\text { participation, etc }\end{array}$ \\
\hline 2012 & $\begin{array}{l}\text { Basic information, employment, housing, medical insurance, marriage, children, access to } \\
\text { family planning services, etc }\end{array}$ \\
\hline 2013 & $\begin{array}{l}\text { Basic information, employment, income and spending, access to public services, social } \\
\text { security, marriage, children, access to family planning services, etc }\end{array}$ \\
\hline 2014 & $\begin{array}{l}\text { Basic information, employment, income and spending, access to basic public health and } \\
\text { medical services, etc }\end{array}$ \\
\hline 2015 & $\begin{array}{l}\text { Family members, income and spending, employment, access to basic public health services, } \\
\text { access to medical health for seniors, etc }\end{array}$ \\
\hline 2016 & $\begin{array}{l}\text { Family members, income and spending, migration \& employment, willingness to settle down } \\
\text { in destination area, access to medical and family planning services, etc }\end{array}$ \\
\hline 2017 & $\begin{array}{l}\text { Family members, income and spending, employment, migration, willingness to settle down } \\
\text { in destination area, access to medical and public services, etc }\end{array}$ \\
\hline 2018 & $\begin{array}{l}\text { Family members, income and spending, employment, access to medical and public services, } \\
\text { etc }\end{array}$ \\
\hline
\end{tabular}

Moreover, the National Health Commission makes CMDSs data available to download, benefiting a myriad of researchers from prestigious universities and research institutes in China and abroad. Using this data, scholars have published 
numerous influential academic monographs, research papers and dissertations. According to statistics from relevant authorities, a total of 223 universities and research institutes across China have obtained CDMSs data, with the data sharing platform attracting more than 13,000 registered users, including institutions, organizations, and individuals from sectors such as education, health, transportation, planning, finance, publishing, consulting, big data, marketing, and others.

\section{Prospects}

With the advent of the new era, population migration has become and will continue to remain a decisive factor influencing China's demographic transition. The scale and frequency of population migration, the characteristics and socioeconomic structure of migrants, and the causes and directions of migration are all undergoing constant changes. Accurate projection of short-term and mid- to long-term trends of the size of the migrant population and the types and frequency of population migration can provide a reliable basis for formulating regulations, plans and policy arrangements best aligned to the realities of China. Changes in the situation of the migrant population have given rise to new topics and new tasks for research on migrant population. Such research will require sustained and in-depth surveys to a basis for the development of theory (Duan \& Cheng, 2018).

After the results of census 2020 announced, the size of migrant population reached a new peak of 376 million. However, it is necessary to grasp the trends and characters of migrant population by using some data. CMDS served as the only continuously and nationally representative migrant survey, and data from it played a major role in migration-related research and policy making in China. When the new data is no available, it is important to take advantage of IT to support understanding and studying the migrant.

The Internet age has brought with it a host of new technologies and new methods. A combination of mobile signaling data, the Internet, and smart wearable devices can help map the distribution of China's population, record the trajectory of population movement, and make visible the exchange of goods, funds, technologies and ideas behind population movement. In particular, although the actual number of people that move on a given day cannot be shown by population census or demographic data, mobile positioning big data offers an alternative that provides strong data support and a new research perspective to unravel the daily movements of urban populations. The high sampling rate and fine time granularity of mobile positioning big data can give us considerable insight into the regularity of population migration (Wang \& Ren, 2020).

Regarding the future, first CMDSs should put greater emphasis on supporting and serving population development strategies, aligning itself to the needs of new urban planning and rural revitalization efforts. The surveys should continuously monitor the spatial distribution of China's population, and observe such two phenomena as population gathering towards urban agglomerations, and the shrinkage of permanent resident populations in certain areas, that may take place simultaneously. Second, CMDSs should make comprehensive use of existing IT applications and emerging 
technical processes to match government's administrative data with survey data, improve the quality of the sampling frame while minimizing non-sampling errors in the survey, enrich the coverage and methods of surveys, explore various survey methods such as online surveys and telephone surveys, and continuously improve the technical operations of the surveys, thereby harnessing the technological dividends of the new technology era. Third, to broaden its influence, CMDS should make full use of social resources to push forward the application of survey data and the promotion of survey results, to establish a comprehensive mechanism for using data to support decision-making and to serve the society, to gradually make a change to the one-way feedback mechanism for survey results, and to explore ways to integrate research results into the survey so that respondents can enjoy the fruits of the survey more directly.

\section{Declarations}

Conflict of interest The authors declare no conflict of interest.

Open Access This article is licensed under a Creative Commons Attribution 4.0 International License, which permits use, sharing, adaptation, distribution and reproduction in any medium or format, as long as you give appropriate credit to the original author(s) and the source, provide a link to the Creative Commons licence, and indicate if changes were made. The images or other third party material in this article are included in the article's Creative Commons licence, unless indicated otherwise in a credit line to the material. If material is not included in the article's Creative Commons licence and your intended use is not permitted by statutory regulation or exceeds the permitted use, you will need to obtain permission directly from the copyright holder. To view a copy of this licence, visit http://creativecommons.org/licen ses/by/4.0/.

\section{References}

Duan, C., \& Cheng, M. (2018). Deepen the research into population migration in the new era. Population Research, 1, 27-30 (in Chinese).

Duan, C., Liang, H., \& Wu, X. (2002). Summery on the investigations of China's population migration and mobility in the past two decades. Market \& Demographic Analysis, 1, 55-59 (in Chinese).

Qi, J., Qin, M., \& Li, B. (2014). Reflections on the sampling design of migration surveys. Statistics and Decision, 3, 14-16 (in Chinese).

Wang, D., \& Ren, X. (2020). Distribution and composition of actual population in urban space from daily human mobility view. Urban Planning Forum, 2, 36-43 (in Chinese).

Zhuang, Y., \& Li, B. (2014). Reflections on sampling of migrants surveys. Population Research, 1, 30-36 (in Chinese). 

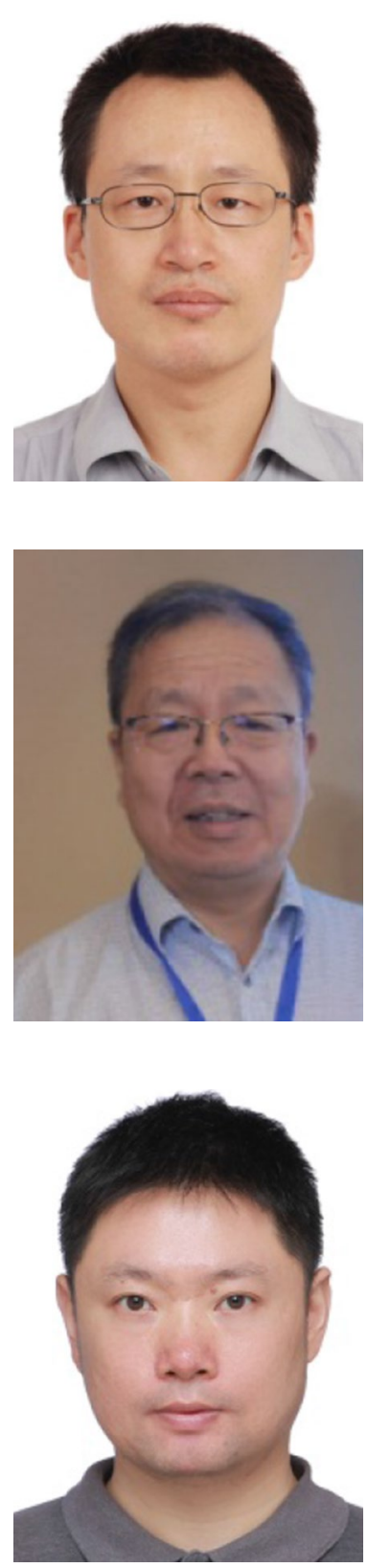

Zhili Wang is an associate research fellow of China Population and Development Research Center, Beijing, 10081, China. His research interests include migrant and fertility.

Qian Wang is the head of former Department of Migrant Management and Service, National Health and Family Planning Commission of the People's Republic of China.

Jianan Qi is senior research fellow of China Population and Development Research Center, Beijing, 10081, China. His research interests include survey methodology, urbanization and migration of China. 